\title{
A review of management of infertility in Nigeria: framing the ethics of a national health policy
}

\author{
Oluyemi Akinloye ${ }^{1,2}$ \\ Ernest J Truter ${ }^{2}$
}

'Department of Chemical Pathology, Reproductive and Molecular Endocrinology Unit, College of Health Sciences, Ladoke Akintola University of Technology, Osogbo, Osun State, Nigeria; ${ }^{2}$ Department of Biomedical Sciences, Faculty of Health and Wellness Science, Cape Peninsula University of Technology, Bellville Campus, Cape Town, South Africa
Correspondence: Oluyemi Akinloye Department of Biomedical Sciences, Faculty of Health and Wellness Science, Cape Peninsula University of Technology, Bellville Campus, Cape Town,

South Africa

Tel +27 21 9596697

Fax +27 21 9538490

Email oluyemiakinloye@hotmail.com
This article was published in the following Dove Press journal:

International Journal of Women's Health

10 August 2011

Number of times this article has been viewed

\begin{abstract}
Infertility has recently been construed to be a serious problem in sub-Saharan Africa. This problem seems to be viewed as of low priority with reference to the effective and efficient allocation of available health resources by national governments as well as by international donors sponsoring either research or service delivery in the public health sector. In this paper the problem of infertility in Nigeria is surveyed with a view to assessing the ethical dimension of proposals to manage infertility as a public sector priority in health care delivery. The population/individual and public/private distinction in the formulation of health policy has ethical implications that cannot simply be ignored and are therefore engaged in critically assessing the problem of infertility. Cost-utility analysis (such as Quality Adjusted Life-Year composite index) in the management of infertility in Nigeria entails the need for caution relevant to the country's efforts to achieve Millennium Development Goals. This should remain the case whether the ethical evaluation appeals to utilitarian or contractarian (Rawlsian) principles. The "worst off" category of Nigerians includes (1) underweight children less than 5 years of age, with special concern for infants ( $0-1$ years of age) and (2) the proportion of the population below a minimum level of dietary consumption. The Rawlsian ethic implies that any Federal Ministry of Health policy aimed at establishing public programs for infertility management can be considered a "fair" allocation and expenditure if, and only if, the situation for these two cohorts is not thereby made worse. Nigerian health policy cannot assume this type of increased allocation of its resources to infertility care without it being hard pressed to warrant defensible moral or rational argument.
\end{abstract}

Keywords: infertility, bioethics, health policy, Nigeria

\section{Introduction}

A recent issue of Nature described the problem of infertility in sub-Saharan Africa to be "rampant on the continent." For the purpose of this discussion, we shall adopt as a definition of infertility that set forth in the guidelines of the Royal College of Obstetricians and Gynaecologists (UK): "failure to conceive after regular sexual intercourse for two years in the absence of known reproductive pathology." 2 This definition excludes both moderate and severe subfertility couples, given that, (1) " $71 \%$ of moderately and $21 \%$ of severely sub-fertile couples conceive spontaneously within 2 years," (2) "95\% of moderately and $45 \%$ of severely sub-fertile couples conceive within 5 years," (3) "few treatment interventions have been proven to be effective in improving impaired chances of conception in cases of subfertility," and it is important also to exclude adolescent subfertility given the ongoing development of the reproductive function of this age cohort. ${ }^{3}$ 
The very idea of rampant infertility in sub-Saharan Africa may be unfamiliar to foreigners, as they are accustomed to reports of ubiquitous poverty and high rates of morbidity and mortality from infectious and parasitic disease. They are also alerted to a growing prevalence of chronic degenerative diseases, all compounded by severe malnutrition and basic impediments due to inferior environmental quality. That infertility can be construed an "urgent" problem in subSaharan Africa seems quite beside the point of effective and efficient allocation of available health resources by national governments as well as by international donors sponsoring either research or service delivery in the public health sector. Recommendations for adjustment to national health policies seem all the more out of place relative to recently adopted population-planning policies and the actual cost of infertility treatment facilities. Van Zandvoort reports that to establish an assisted reproduction technique (ART) unit according to international standards costs US $\$ 400,000$ to US $\$ 500,000$. $^{3}$ In this paper, the problem of infertility as found in Nigeria is discussed, with view to assessing the ethical dimensions of proposals to manage infertility as a public sector priority in health care delivery.

\section{Infertility in Nigeria}

Fertility rates in Nigeria have been put at approximately six children per woman ${ }^{4}$ notwithstanding a "high rate of pregnancy wastage. ${ }^{5}$ The World Health Organization World Health Report ${ }^{6}$ shows a value of 6.5 children per woman for 1994 and 5.7 for 2004. These data seem at odds with growing concerns about infertility as such. As Hollos 7 put it, "The problem of infertility in sub-Saharan Africa (including Nigeria) received comparatively little attention until recently." Hollos further emphasized that the problem of infertility "was obscured by the region's high fertility rates, which gave rise to a global climate of concern over population growth and high fertility that is not conducive to the perception of infertility as a real problem."

However, Okonofua reports that, of 780 couples visiting the reproductive health clinic of the Women's Health and Action Research Centre in Nigeria in 2002, more than half were found to have severe causes of infertility. ${ }^{8}$ Araoye reported that the major cause of infertility in Nigeria is infection: sexually transmitted diseases (STDs) and postarbortal and puerperal sepsis, with the problem by no means restricted to women. ${ }^{9}$ However, male infertility is regarded as taboo, a problem that no one will admit exists. ${ }^{10}$ This taboo itself is a contributor to practices of polygyny, with women all too frequently assumed by the local population to be the primary culprit of infertile marriages, and male infertility is handled with discretion to protect male dignity. ${ }^{4}$ Previous studies in Nigeria have focused on the possible contributions of environmental factors, such as diets and toxic elements, ${ }^{11-13}$ sociocultural behaviors and sociodemographic factors, ${ }^{14,15}$ infection, ${ }^{16,17}$ and hormones. ${ }^{18,19}$

Studies seeking to characterize the genetic background of infertility in Nigeria have indicated that about $39.5 \%$ of the normozoospermic population has reduced CAG repeats and a lower percentage of the infertile population (23\%) has shown moderately increased repeats. ${ }^{20}$ Such studies may have serious implications for making decisions on treatment strategy, especially hormonal replacement therapy in hypogonadism. Patients affected by some forms of genetic alterations produce a higher frequency of sperm with aneuploidies; hence, an increased risk of congenital abnormality in the fetus exists as produced by in vivo fertilization or intracytoplasmic sperm injection (IVF/ICSI). ${ }^{21}$ Moreover, genetic conditions may also be transmitted to the offspring, thereby creating transgenerational infertility or other health problems.

Setting aside statistical data to glance at the individual faces of infertility, one frequently finds women (rather than men) whose personal stories are cause for indignation and ethical concern, as the news feature in Nature ${ }^{10}$ makes starkly clear: several years ago, Betty Chishava was thrown out of her family home in Harare, Zimbabwe, because she had failed to fall pregnant and did not want to sleep with her husband's brother. Desperate for an heir and a cure for the stigma of infertility, her husband Herbert took a new wife. Betty was left penniless and alone. A similar picture is painted in an article published in Population and Developmental Review ${ }^{22}$ : Kaddy Sisay, a 30-year-old remarried divorcee had carried at least four pregnancies. Three were with her first husband. The firstborn, a daughter who died before age 3 years, was followed by two stillbirths. At this point Kaddy's marriage ended, very likely as a consequence of her failure to produce children for her husband. Remarrying as the marginal second wife of a man already married to a younger woman with three children, Kaddy became pregnant for the fourth time and bore another son when she was about 21 years of age. This child died and Kaddy was left in a precarious marriage with no children to support her in later life.

Consider next the example of Jeannette, ${ }^{7}$ who, at 31 years of age, manifested secondary infertility after the birth of a male child and suffering four miscarriages. Her concern was that when she gets old there will be nobody to help her. She did not believe that her husband's children (from other wives) would help her. She also knew that when her husband died 
she would have to go back to her home community, since she would have no right to remain in his compound. His son (from another wife) would come back and force her out of her matrimonial home.

The foregoing examples disclose how infertile women become marginalized and are forced to find "coping mechanisms" as they move from initially monogamous marriages to situations of polygyny with a corresponding change in rank order of wives relative to manifest fertility. The lack of proper management of male infertility also means that women are forced to be more persistent about seeking treatment, adding unnecessarily to the burden upon reproductive health service resources, limited as they are in developing countries. ${ }^{3}$ For women facing traditional perspectives on life, infertility becomes a radical "lifealtering problem." The fact is that infertility carries with it significant psychological trauma, such that it is meaningful to speak of "health-related quality of life" concerns for infertile women. ${ }^{23,24}$ Data from studies continue to show that $5 / 10$ girls and $7 / 10$ boys have had sexual intercourse at least once by the time they leave secondary school. ${ }^{25}$ Further, extramarital infidelity among men is more tolerated than among women, especially where infertility contributes to the practice of polygyny. Hence, local custom and cultural determinants of belief and behavior are wholly central to a meaningful understanding of the problem, even as those involved in infertility treatment by way of advanced methods of reproductive technology work to propose "methods for developing simpler, low-cost alternatives to the high-tech drugs and equipment currently used for fertility treatments." 10 At the same time, health promotion and education on sexual practices are equally (if not more) important given the primary cause of infertility in preventable STD infection.

Without doubt, there are questions of resource allocation here that involve the more general ethical question of achieving distributive justice within the public health and private medical care sectors. Nigeria, for example, experienced its first successful use of IVF in 1989, yet Giwa-Osagie remarked recently that, despite that success, the nation's budget priority in health care continued to be given to the high visibility diseases such as malaria and diarrhea. ${ }^{10}$ This remark manifests an assumption that biomedical research and consequent successful employment of biomedical technologies entail more large-scale commitment of the public's resources. This as an expression of a permissible, if not mandatory, shift in priorities. Yet, as van Balen and Gerrits $^{26}$ remarked, "emphasizing the need to formulate a policy on 'how to deal with infertility', does not necessarily imply that new reproductive technologies (NRTs) should be introduced and financed by the public health system." In published work, Okonofua has "cautioned that such an approach would be inappropriate as the new reproductive technologies are not likely to be cost-effective in resolving infertility in Africa, and could reduce available funds needed to address other escalating health problems." 27 In the case of Nigeria, the nation's attention to high-visibility diseases and thereby to vulnerable population groups is commendable and considered a right response to fulfillment of Millennium Development Goals (MDGs). However, the African response to MDGs, 5 years into her implementation, is particularly slow, especialy throughout sub-Saharan Africa. GiwaOsagie's remark also does not account for the distinction between the goals of medicine and those of public health, within the national context of policy formulation. ${ }^{10}$ This by no means diminishes the value of Giwa-Osagie's perspective. ${ }^{10}$ However, his perspective does not adequately account for the ways in which private medical care is delivered in Nigeria. Alubo $^{28}$ acknowledges that "irrespective of source, health care development in Nigeria is largely limited to curative services, with prevention, promotion, rehabilitation and other aspects receiving attention only on paper." But, Alubo has argued effectively that there are important "limitations of private medicine in addressing the prevailing burden of disease and death in Nigeria," including the fact that the "for-profit motive and high fees also limit access to private medical enterprise (PME) services": "The fee regime means that most people cannot afford the services in a country of high and rising poverty and unemployment. In effect, only clients covered by some third party arrangements such as retainership can afford PME services." 28 Thus, it will often be the case that the goals of medicine as expressed by physicians practicing in the private sector will necessarily (thus, with defensible ethical warrant) be subordinated to those of public health, given the country's pattern of disease and the resources available in the public sector and under the purview of a ministry of public health. This is all the more so in a case such as Nigeria, which has a national health system per capita expenditure of US\$9.44. ${ }^{29}$ Infertility as a problem faces stiff competition for available resources in this context. Given that "current health spending in most low-income countries is insufficient for the achievement of the health MDGs," it is debatable that infertility reasonably has a place in public sector financing, though it has a place in privately financed options via established fertility clinics in Nigeria. Clinics in Lagos and Port Harcourt have "state-of-the-art laboratories," performing "more than 500 cycles of IVF 
treatment a year." 10 The contrast is patently clear relative to public and private resource availability: "In Nigeria a single IVF treatment costs around US\$2500. But the minimum wage in Nigeria is just US\$52-US\$60 a month and there are a great many people scraping by on a dollar a day, or less," 10 with "those lucky enough to have jobs" receiving "on average the equivalent of US\$30 a month." ${ }^{28}$ Thus, it comes as a surprise to many involved in global health policies that researchers "are lobbying hard to put African infertility on the international agenda." 9 Research in progress for lowercost alternatives to state-of-the-art IVF is yet to move beyond the laboratory to clinical trials. Hence, the ethics of ART use in sub-Saharan Africa are yet to be properly engaged as proposals move forward for public sector responses to infertility, even in Nigeria.

WHO and those working to implement and attain the MDGs make it clear that, "Progress will equally depend on getting policies right, making the institutions that implement them function effectively, building health systems that work well and treat people fairly and ensuring there are enough staff in post to do all the work." ${ }^{30}$ In the case of Nigeria this would include an increase in per capita expenditure within the health system from US\$9.44 to US\$34 as recommended by the WHO. Of course, as former WHO Director-General, Dr Lee Jong-wook, conceded, "The MDGs do not say everything that needs to be said about health and development" - and he specifically mentioned reproductive health as one of the needs not included in the MDGs. ${ }^{30}$ Nonetheless, to characterize the MDGs as "the most important outcomes that development should achieve" is to prescribe the basic focus of concerted collaborative action from national governments, international governmental and non-governmental organizations, and donors. Given the sociocultural context of Nigerian infertility, however, it would seem that any arguments favoring public sector allocations would have to relate to either the MDG of "gender equality" or "maternal health" or both. But, this argument is for the moment lacking.

\section{Issues of cost-effectiveness}

It has been said, quite correctly, that, "Every [medical] practitioner is motivated to maximize outcome." 31 This is so even for the infertility specialist and is consistent with traditional practitioner obligations such as nonmaleficence and beneficence. The problem here, however, is to specify the outcome in the management of infertility, beginning with diagnostics, exploring relevant treatments short of ART, and then committing to one or another ART intervention in the given case, but with attention paid to reasonable cost-effectiveness. ${ }^{32}$ Developing countries such as Nigeria, on the verge of public policy commitments to infertility care stand to learn from mistaken approaches to the management of infertility in developed nations, especially on the question of outcomes assessment, even as they may find reason for caution in structuring national policy, given available cost data, eg, for IVF, which varies significantly by age (eg, in Thailand the cost for IVF delivery for women $<38$ years $=£ 9,747$ [US\$15,500] while that for women $>38$ years is $£ 38,946$ [US\$62,500]). ${ }^{33}$

Moreover, it has been argued ${ }^{31}$ that, "most infertility treatments have entered the clinical mainstream without prior outcome assessment." If the practitioner's comportment is one of maximizing outcome, it is important that a ministry of health in a developing country like Nigeria be clear about what outcomes it seeks in the management of infertility such that it can pursue allocative decision-making responsibly. Surely in Nigeria the expected and/or authorized outcome cannot be that of maximizing conception rates because, as Gleicher ${ }^{31}$ points out, such an outcome measure will simply lead to "indiscriminate" practices (eg, multiple implantations) that result in "higher multiple conception rates," which implies "higher clinical risks" and thus "also higher obstetric and neonatal costs" due to "an increase in prematurity and severe prematurity." The cost implications can be staggering: "The neonatal intensive care costs [assuming these services would even be available in a developing country such as Nigeria as part of a reproductive health policy, planning, and programming scheme] of a single very premature infant can exceed the total infertility costs of hundreds of couples." 31 This does not include maternity post-partum care, which adds further to the cost factor. These are not costs that public sector financing can accommodate readily as the outcome of infertility treatment is engaged by the available obstetric/gynecological services as well as specialized (neonate) pediatric services. Where there are public-private partnerships encouraged by a ministry of health in such a setting, therefore, there cannot be overemphasis on an important criterion: "The fertility specialist carries a principle [sic] responsibility for obstetric outcome." The policy implication here is that, "the final cost of infertility treatment cannot be assessed until maternal and neonatal outcomes are assessed" "31 (italics added).

The important question, then, is: what is the appropriate outcome expected in the management of infertility if cost-effectiveness analysis is to benefit decision-making and actual health status? ${ }^{31}$ Gleicher answers appropriately: "The appropriate outcome end-point for infertility treatment 
is birth and/or discharge of the mother and neonate after birth rather than conception" (italics added). This outcome thereby accounts for negative externalities associated with pregnancy following ART, given that though conception may occur, there are significant complications that may ensue for both mother and fetus. Thereby, quality of life post-partum for both the (previously) infertile couple and neonate takes center stage.

\section{QALY as a component of ethical review}

A composite indicator of health status such as QALY (quality adjusted life-year) may be appropriate as a measure to inform the allocative decision at policy level. It is a utilitarian method that seeks an objective estimate of consequences, ${ }^{34}$ thus a form of cost-utility analysis ${ }^{35}$ setting forth "the ratio of the incremental cost to incremental effectiveness," the general objective being that of determining "the optimal set of health-care interventions that will maximize societal well being." ${ }^{36}$ It is a measure of health in a population designed to "estimate the quantitative health benefits from intervention," 37 specifically "differences in health benefits at the margin," (italics added) ${ }^{38}$ thus, it is a concern for marginal utility.

QALY also counts as a "summary indicator for burden of disease assessment," and is specifically designed "to provide a guiding principle for selecting among tertiary health care interventions." 36 Thus, alternative interventions are "ranked" in terms of "cost per QALY," with the allocative decision made in preference of those interventions having the lower cost comparatively. The focus on comparison thereby distinguishes cost-effectiveness analysis of QALY from a cost-minimization analysis, where both costs and consequences are considered in the special case where outcomes are shown to be equivalent. ${ }^{39}$ The cost-utility element of the QALY means that, "the opportunity cost of scarce health care resources is defined in terms only of QALYs foregone." 40 This can be done without reference to a budget constraint ("no explicit limit on health-care expenditures"), or it can be a calculation undertaken with reference to an operating budget limit ("maximize QALYs while holding costs within the given health-care budget") (Donaldson and Bate; ${ }^{41}$ as cited by Bala et $\mathrm{al}^{36}$ ). Some health economists recommend using "a specified price per QALY gained rather than a fixed budget as the decision rule," the reason being that, "it is possible to include all the costs in the analysis, instead of only the costs that fall in the specific budget." 42 Whatever the decision rule chosen, one of the attractive features of the QALY as a composite measure is its incorporation of identifiable/identified "preferences for various health outcomes." ${ }^{43}$ Despite such calculations and accounting for preferences the problem still remains from where one is to receive the budget resources and where the utility analysis permits implementation of a program. ${ }^{44}$ Generally, "the rule" in cost-effectiveness analysis is that "the required budget for a new cost-effective therapy has to be taken from the existing less cost-effective treatments in the health care sector." ${ }^{44}$ Of course, this is not to say there are no other disadvantages to using a composite measure such as QALY. As Doctor et $\mathrm{al}^{45}$ noted, "A disadvantage of the QALY model is that it represents individual preferences for health only under restrictive assumptions"; and "Empirical tests of the QALY assumptions have generally yielded negative results." The problem is to know how to measure "expected utility" adequately when comparing alternative health care interventions. One of the difficulties is determining "data for quality," given that "its perception is so personal and variable," even as perceptions of health status will vary with comorbidities (eg, sequelae such as the neurological status of stroke, compounding a primary morbidity such as hypertension), in which case an adequate measure of effectiveness would account for both "the target condition" and "the companion condition." ${ }^{6}$ Since it is a utilitarian measure relating cost to effectiveness, a given use of QALY may not allocate to "the worst off" in a given setting of health care, the argument being that, "the net benefit of the treatment [eg, if the elderly and disabled were considered to be the worst off cohort] would be lower than the net benefit of treatments for younger and generally healthier people." ${ }^{\prime 4}$

This is important in the case of cost-utility analysis in the management of infertility in Nigeria, especially given that the developing country context with its socioeconomic and cultural variables is rather different from that of an industrialized nation. The question remains, importantly, what the QALY composite measure happens to be in a given assessment; the fact is that "the patient in front of us may choose differently," hence, one cannot ignore both the ambiguity and the diversity involved in rational choice available to those who can and should be involved in policy decisions. Lehmann ${ }^{46}$ provides a useful reminder of recommendations made by the US Public Health Service Panel on Cost-Effectiveness in Health and Medicine (1996) that remain relevant to a QALY assessment, eg, (1) "all health effects should be included in the effectiveness measure"; (2) "cost-effectiveness should be evaluated with respect to status quo treatment"; (3) "community preferences should be used"; (4) "the analysis should make a place for adjustment due to age, gender, and race." Further, as Glannon and Moss ${ }^{47}$ observed, allocation 
to the worst off is not inconsistent with a QALY-based justification. They explain the importance of emphasizing that the "priority to the worst off is a conditional rather than an absolute principle." In their opinion, this "depends not only on how much they will benefit (which is what QALYs measure), but also on whether the use of resources for them will limit the use of resources for others who could be raised to the decent minimum." The utilitarian standard, of course, remains central: "The crucial point is to use resources so that the greatest number will be raised to, or remain at, a decent minimum of normal functioning. $" 47$

Generally speaking, nonetheless, the calculations for QALY include the following components ${ }^{38}$ : (1) CostEffectiveness Ratio $=$ cost of services/(health gain $\times$ duration), (2) Cost of Services = charges for treatment, including all services and drugs, (3) Quality of Well-Being = sum of "severity weight" (W), each W state the probability that QWB state would occur, (4) Health Gain = QWB with treatment - QWB without treatment. It has been noted ${ }^{48}$ that, "The point of an allocation scheme such as the QALY is that it is to be objective by being independent of the preferences and prejudices of the allocator." This comportment is consistent with the utilitarian desideratum of impartiality and benevolence in the decision.

Thus, "A system of resource allocation based on QALYs may actually aid a more equitable distribution of health care, since QALYs (if properly elicited) are valued the same no matter whom they accrue to." ${ }^{38}$ QALY, of course, will involve subjective assessments of quality of well-being, even if there are sample surveys designed specifically to collect psychometric data from patients and practitioners involved in the treatment of given medical conditions. It is now more or less accepted practice that studies include sensitivity analyses to assess the impact of uncertainty surrounding health-state values on final estimated cost effectiveness ratios. ${ }^{44}$ This will be the case also for assessments of alternative approaches to infertility in a developing country such as Nigeria. Those involved in ART biomedical research more often than not are clinical researchers concerned with the application of ART relative to observed or projected "direct clinical effect" rather than being concerned with quality of life assessments per se. Thus, various ART option are stated in terms of "average cumulative pregnancy rate." ${ }^{49}$ Yet, it is the quality of life assessment that provides meaningful decision-making evidence where health policy analysis is designed to assist in resolving resource allocation dilemmas.

Quality of life assessment in the case of Nigerian men and women suffering from infertility will include both a disability score (DS), representing physical impairment in reproductive/ procreative function $[0=$ no disability; $1=$ equivalent to death], as well as a social distress modifier (SDM) across several rating levels [A. None; B. Mild; C. Moderate; and D. Severe]. As noted earlier, the WHO Global Burden of Disease Report assigned infertility to disability level 3 out of 7 categories, for a "severity weight" ("how incapacitated the person is as a result of the disease") of $0.12-0.24$ (ie, $12 \%$ to $24 \%$ incapacity of normal function). A further operative assumption in the QALY scheme is that immediate benefits from a particular health care intervention are more valuable than future benefits, hence the need for discounting (eg, use of a $5 \%$ discount rate over a selected period of time, eg, 15 years..$^{50}$ Discounting is particularly important in comparing interventions associated with treatment in contrast to those aimed at prevention. The fact is that, " 'Identified' lives saved by treatment in the present hold more influence than 'statistical' lives saved in the future by an equivalent investment in prevention," as Phillips and Holtgrave ${ }^{32}$ have observed. Accordingly, they point out that since the benefits of prevention occur mainly in the future, while the costs of prevention occur primarily now, the process of discounting then affects the cost-effectiveness of prevention. They also report that since "the benefits of treatment occur more often in the present ... discounting tends to have less impact on its calculated cost-effectiveness." There is also the factor of preference associated with income status: "individuals with lower incomes often value future benefits less than those with higher incomes," ${ }^{32}$ hence the importance of using a standard "social discount" rate. ${ }^{51}$

Consistent with the foregoing, then, quality of life assessment will also have to consider the comparative value of (A) alternative treatments for the affected sub-group of the population suffering infertility and (B) strategies of prevention (health education/health promotion) for the sub-group of the population at risk of infertility but not yet in a position to require treatment as such. (A) can include medical treatment for primary STI such as gonorrhea and Chlamydia trachomatis as well as specific infertility treatments (eg, gonadotrophin drugs), surgical treatment (eg, surgical correction of epididymal blockage, tubal microsurgery), and assisted reproduction (eg, IVF, ICSI, artificial insemination by donor), thus medical management of both male- and female-factor fertility problems. (B) would include the panoply of interventions aimed at prevention of STDs in both men and women whose infertility is etiologically linked to STDs deriving from unsafe sexual practices and sequelae of STI, hence the importance of risk-reduction investigation (including contact tracing) 
and treatment. Because of logistical difficulties associated with contact tracing in a developing nation context of programming, it may be that risk-reduction would be initiated through screening for incidence/prevalence rather than tracing contacts as such. The point to bear in mind here is that whatever the policy choice between (A) and (B), or, more likely, a choice of some mix of (A) and (B), the fact is that "many interventions can have an impact on quality of life and that these need not be medically necessary or essential interventions" - the implication of which is that, "we need to have non-arbitrary criteria [sic] for ruling in particular interventions for consideration. ${ }^{" 56}$ However, there is a further point at issue here: "we need to have rules about whose quality of life is to be counted and how it is to be estimated." 48 Here justice in resource allocation (distributive justice) elicits the ever-present question of entitlement: Who is entitled to what services within the available resource constraints and restraints on performance? This is important in the case of programming in reproductive health care given that the annual cost per participant will vary across public health and clinical interventions. For example, WHO bank data for 1993 estimated cost per participant in low-income countries: health education (including family planning, nutrition information) about US\$2.4 per participant; AIDS prevention about US\$112 per participant; prenatal and delivery care about US\$90 per participant; family planning about US\$12 per participant; treatment of STDs about US\$11 per participant. ${ }^{52}$ These cost estimates do not include costs associated with infertility treatment. Ikechebelu ${ }^{49}$ reports a cost of N400,000 (US\$2565) for IVF treatment in Nigeria and considers the preference for diversion of funds to primary health care both "parochial and prejudicial" (though with the concession that ART is to be considered a legitimate choice "for those who can afford it and desire to have a child of their own").

\section{The ethical dilemma and alternative theoretical dispositions}

Health policy scholar Larry Churchill ${ }^{29}$ commented, "ethical problem solving without the benefit of theoretical reflection is like digging a garden with one's bare hands rather than using the appropriate tools," even as one may reasonably say, in balance, "theoretical reflection that is untested by involvement in the concrete particulars of life is like reading about gardens without ever planting and tending one." The foregoing question - "Who is entitled to what services within the available resource constraints and restraints on performance?" - attests to the problem of identifying standards of assessment. This is a problem of ethics, given asserted claims of entitlement to specified services.

The question is: if an infertile couple in the UK (or similar industrialized nation) can lodge an entitlement claim to infertility care merely on the basis of a general right to health care under purview of the National Health Service, may an infertile couple in Nigeria (or similar developing country) do likewise, and do so insisting that there should be no "double standard" in the administration of a "fair" health care opportunity from its own Federal Ministry of Health? In other words, if some service/intervention is considered to be medically sound or valid in the UK, ceteris paribus, is that service/intervention reasonably to be affirmed to be acceptable in Nigeria? Arguments may be provided either way, without ready resolution of the point at issue. McMillan, ${ }^{53}$ for example, has argued in favor of construing infertility treatment as a medical need given its associated disruption of normal (reproductive) function and, thus, a limitation of fair equality of opportunity (pregnancy, being a parent, raising a family, and so on) that resource allocation decisions should therefore address. Medical need would then be one plausible reason to support a national policy to manage infertility. The problem here, however, is that any application of a concept of medical need is faced with charges of "ambiguity, indeterminacy, subjectivity [and] value-ladenness, ${ }^{54}$ hence recommendations by some health economists to engage preferences rather than needs. Infertility care would then be more reasonably construed to be a preference of varying intensity for those seeking such care alternative to a focus on preferences is to engage "basic needs" defined as "needs requisite for sustaining life," and such needs are "considered to be directly related to required courses of action without which a patient ceases to be functional. ${ }^{\prime 54}$ The question here is whether the argument can be made defensibly that the management of infertility in a setting such as Nigeria is regarded as a response to a basic need. That is an unlikely argument, in which case Cohen's caution that it is important if one is to use QALY as a measure: "the issue of what QALY analysis measures, in particular what the quality of life adjustment factor measures, is one that should be examined before one can constructively discuss distributional principles. ${ }^{54}$ Yet, the fact is that decisionmaking in the health sector is unavoidably faced with real resource constraints and uncertainty in projected outcomes, whatever one's commitment theoretically or ideologically as a matter of political economy or moral philosophy. ${ }^{55}$ The resource constraints for Nigeria are no less real and palpable for both the public sector under the purview of the Federal 
Ministry of Health as well as for the private sector, the latter responding as best it can to be consistent with private fertility clinics and fee-for-service pay schemes (that are more often than not "out-of-pocket" as they enjoy private insurance or retainerships).

Even a resource-capable country such as the UK with its National Health Service (NHS) cannot implement such a policy without accounting for a shift in demand for services. For example, in setting forth guidelines for the clinical management of infertility, the National Institute for Clinical Excellence (NICE) provides costing information along with clinical guidelines. ${ }^{56}$ Implementing the new clinical guidelines entails significant cost considerations: (1) $70 \%$ of current privately treated patients could demand NHS treatment, thus expanding the public cost burden; (2) the cost of substitution (private demand becoming NHS demand) would be about $£ 33.3$ million with the cost of growth being $£ 50.6$ million, for a total cost impact of $£ 83.9$ million; (3) there would be an additional ongoing increase in the level of IVF services demand over time; (4) an $80 \%$ increase in IVF provision would entail $66 \%$ more babies born, $27 \%$ of these babies being premature births requiring neonatal intensive care, so that the NHS would experience an increase of $£ 4.1$ million in neonatal intensive care costs; (5) total cost impact of implementing the clinical guidelines (after accounting for some savings elements) is $£ 81$ million. The foregoing cost data are instructive in pointing to the fact that the mere formulation of a policy and setting forth implementation (clinical) guidelines entails a serious cost impact. This is no less the case in a developing country and, thus, for any advocacy on behalf of an infertility policy to be implemented by the Nigerian Federal Ministry of Health. In fact, the cost implications are even more severe in the case of a developing country such as Nigeria where pregnant women do not enjoy optimal nutrition but experience deficiencies that lead to anemia and exposure to risk of infection. ${ }^{57}$

So, the ethical question remains: how is one to respond to the assorted infertility care interests expressed here insofar as these interests have a bearing upon the formulation of a national health policy in Nigeria? Let us consider this question in terms of the debate within an ethical theory between those who advocate a utilitarian approach to the allocative decision and those who advocate a justice as fairness ("contractarian") approach - the ethical decision then being gauged in terms of a commitment to either a principle of utility (or principle of "average" utility, as argued by Harsanyi ${ }^{58}$ ) or the difference principle (as articulated by John Rawls). Here it is instructive to consider the arguments presented for the Rawlsian approach to ethics and health policy, presented by Danis and Sepinwall ${ }^{29}$ and then assess that position in relation to the criticisms of Rawls's theory as presented by Harsanyi. ${ }^{58}$ Presumably, arguments in favor of "justice as fairness" as applied to health sector decision-making generally could be articulated more specifically relative to the problem of infertility in a developing country setting of decision, even as the utilitarian argument can be likewise developed for the purpose of comparative instruction.

Danis and Sepinwall assert, reasonably enough, that we can adduce plausible hypotheses about pathways that link social inequalities to health, that justice requires that we ask whether social determinants of health are fairly distributed and that where they are not fairly distributed we are to take steps to address the sources of health inequality. Danis and Sepinwall ${ }^{29}$ consider a series of evidence claims about social determinants of health, making it clear on empirical grounds that income/health gradients (eg, life expectancy in relation to gross domestic product per capita) are not the result of some fixed or determinate laws of economic development but instead are influenced by policy choices. Further, they argue, income/health gradients are not merely the result of deprivation of the poorest groups but operate across the whole socioeconomic spectrum within societies - and this would hold true for a developing economy as well. There are identifiable social and psychosocial pathways through which inequality produces its effects on health status (eg, income inequality leads to educational inequality which leads to health inequality). These causal pathways are amenable to specific policy choices that can and should be guided by considerations of justice. Hence, it is important that we consider what theoretical approach to justice is sufficiently defensible for the purpose of making health policy choices.

The question at issue here is how those suffering the problem of infertility are to be evaluated with respect to their interest in fertility care, but relative to the criterion stipulated by the difference principle. According to the Rawlsian scheme, every policy, thus including any proposed policy to manage infertility, is to be evaluated by accounting for the impact that implementation of the policy would have on "those worst off" within the given society (impact positive and/or negative, including externalities). Hence, the empirical question is unavoidable: "Who, among Nigerians in this case, count as the 'worst off,' and according to what measure(s)?"

Before engaging this question, however, let us contrapose to the Rawlsian approach the utilitarian theoretical perspective. In preferring the Rawlsian approach, Danis 
and Sepinwall ${ }^{29}$ distinguished between what they called "identified victims" ("those who are ill and who have known needs") and "statistical victims" ("those whose lives would be spared illness by robust public health measures and a fair distribution of social determinants" of health). As they rightly say, utilitarians "would then push us immediately to maximize net benefit by allocating resources from saving identified victims to saving statistical ones." They would do so only on the basis of a commitment to impartiality in decision and allocation. Harsanyi ${ }^{58}$ identifies this as an "equiprobability assumption," ie, "an expression of the purely moral principle that, in making basic moral value judgments, we must give the same a priori weight to the interests of all members of the society." If here the identified victims are (for purposes of the present argument) the set of men and women who have been identified as infertile couples, then the estimated benefits and costs may very well mean that "the greatest good" (ie, health status by a set of measures of mortality/morbidity/composite rates) for "the greatest number" of Nigerians entails a significant restriction on allocation of available public resources to the identified infertile couples and preference in allocation (because of the cost-effectiveness or cost-benefit ratio) for the public at large (statistical victims) who stand to benefit from prevention measures. The utilitarian seeks to maximize expected utility (net benefit) from alternative policy/program options, such that the cost-effectiveness or cost-benefit calculation may very well entail the commitment of disposable resources to the statistical victims rather than to the identified victims.

The contrast between the Rawlsian and utilitarian approaches is evident. In both cases identified victims (infertile couples) will surely have their personal preferences, expressed as a pressing need and demand for treatment of their infertility with the intended medical outcome being a live birth without maternal complications or infant prematurity and need for intensive neonatal care not to mention the social and psychological outcomes. In the utilitarian approach it is expected that one can assume the position of the identified victims yet suspend judgment of the value of their particular interests, then view the prospective allocation options impartially, without granting priority to anyone whatever their current health status, socioeconomic status, and so on. That is, while taking the utilitarian approach even the identified couples would manifest "a serious attempt. But when taking the Rawlsian approach, the identified couples would expect their own needs/interests in infertility care to be satisfied if, and only if, those worst off among the Nigerian populace are not thereby made worse off, in accordance with the difference principle. Thus, infertile couples individually and as an aggregate would defer to the needs/interests/preferences of those worst off and weight this group's needs/interests/ preferences in health care accordingly.

Let us consider the central question presented by the Rawlsian approach: "Who, among Nigerians in this case, are considered to be the 'worst off,' and according to what measure(s)?" The answer to this question can be given defensibly in empirical evidence associated with MDGs (to which the Government of Nigeria is committed as a matter of policy); and here "the worst off" is referred to as (1) underweight children less than 5 years of age, with special concern for infants ( $0-1$ years of age), thus attention to the 0 - to 5-year-old age cohort in the interest of reducing infant and child mortality and morbidity; and (2) the proportion of population below minimum level of dietary energy consumption. This means, under the Rawlsian ethic, that any Federal Ministry of Health policy aimed at establishing public programs for infertility management can be considered a "fair" prospective allocation and expenditure if, and only if (1) and (2) cohorts are not made worse off thereby. A fair determination of this datum requires that we consider the projected cost-effectiveness or cost/benefit ratio associated with infertility management of the "identified victims" (thus, prevalence/incidence data) and outline the opportunity costs (ie, the benefits foregone from not allocating those resources to [1] and [2] program options).

For the purposes of this analysis (to illustrate the point), we may use the survey value of $17 \%$ infertility for the 20 to 44 -year-old cohort in Nigeria. ${ }^{59}$ Whatever the policy, there is an unavoidable budget constraint on decision making. The operating assumption of available resources of the Nigerian health system is the WHO-recommended (optimistic) figure of US\$34 per capita expenditure, while recognizing, of course, that it is more probable the per capita expenditure for health care will barely approach US\$15 in the years remaining to achieve the MDG objectives up and through 2015. Since those "worst off" among Nigerians include children 0-5 years of age, data from the WHO World Health Report for $2006^{6}$ are relevant: For the year 2004, WHO estimates child mortality (CMR) in Nigeria to be 198 per 1000 (uncertainty in putting the range anywhere between 174/1000 and 220/1000). The age cohort $<5$ years of age for 2005 is estimated at 21.3 million more or less evenly distributed male/female, with growth in this cohort projected to be at 31.7 million by 2025 . With a CMR of 198/1000 this means about 4.2 million Nigerian children $0-5$ years of age die annually. The World Bank reports child 
malnutrition (as \% of children $<5$ years of age) to be $29 \%$, roughly 6.2 million children, with the Food and Agricultural Organization (FAO) reporting $38.3 \%$ of child malnutrition characterized as stunting and $9.3 \%$ as wasting. FAO also reports $9 \%$ of Nigerians as being undernourished for the period 2001-2003 (11.5 million Nigerians), dietary energy consumption in Nigeria for the same period being $2700 \mathrm{kcal} /$ person/day. The foregoing data are to compare with the 20- to 44-year-old cohort estimated to be at 42.7 million, $17 \%$ (7.2 million) of these estimated to suffer (disability/ incapacity) from (mostly secondary) infertility.

\section{Conclusion}

When considering the Rawlsian approach, the difference principle would have us consider whether we can fairly intervene (ie, distribute available resources) on behalf of 7.2 million infertile individuals by whatever treatment regime (1) without making 21.3 million unhealthy children worse off, especially the 4.2 to 6.2 million children whose pattern of infection and disease entails severe malnutrition and/or mortality, and, at the same time, (2) without making 11.5 million undernourished Nigerians worse off as they suffer from inadequate dietary energy consumption.

The realities of a total budget available for the public health care sector, and the high rates of child morbidity and mortality related to the population cohorts as identified above, are starkly clear. Equally clear is the political mandate of the national/federal authority to respond to a significant public health responsibility, given significantly reduced purchasing power among Nigerians for private medical care. In this context of ministry operations, the Nigerian health policy cannot assume the sort of increased allocation of its resources to infertility care (making use of ART), as advocates prefer and now recommend, without finding itself hard pressed, to provide a defensible moral warrant for such a policy and associated programming. Hence, infertility treatment may morally and logically be a low priority for a public funding in Nigeria on macroethical grounds, and is better left to the private sector. A national policy that will empower and create a more productive operating environment for private sectors may be more beneficial. Also from a public health perspective, public sector priority in health care delivery prevention of infertility as one strategy to reduce the number of couples suffering from infertility should be vigorously pursued. It is obvious that from the data available for realistic QALY analysis and related specifically to applied Rawlsian criteria, there is a high probability that the opportunity costs to the worst off Nigerians would be austere once resources are allocated to infertility care. This would then make it a morally indefensible policy.

\section{Acknowledgment}

The authors would like to thank Prof Norman K Swazo of the College of Science and General Studies, Alfaisal University, Riyadh, Saudi Arabia, for the partial review and extensive contribution to this manuscript.

\section{Disclosure}

The authors declare no conflicts of interest in relation to this paper.

\section{References}

1. Cheap IVF needed. Nature. 2006;442(31):958.

2. National Guideline Clearinghouse. Fertility: assessment and treatment for people with fertility problems. Available from http://www.rcog. org.uk/womens-health/clinical-guidance/fertility-assessment-andtreatment-people-fertility-problems. Accessed May 14, 2010.

3. Van Zandvoort H, de Koenig K, Gerrits T. Viewpoint: medical infertility care in low income countries: the case for concern in policy and practice. Trop Med Int Health. 2001;6(7):563-569.

4. Larsen Ulla. Trends in infertility in Cameroon and Nigeria. Int Fam Plan Perspect. 1995;21(4):138-142.

5. Adekunle L. Infertility: a sociological analysis of problems of infertility among women in a rural community in Nigeria. Afr J Med Sci. 2002; 31(3):263-266.

6. World Health Organization (WHO). World health report 2006: working together for health. Geneva: WHO; 2006.

7. Hollos M. Profiles of infertility in Southern Nigeria: women's voices from Amakiri. Afr J Reprod Health. 2003;7(2):46-56.

8. Okonofua F. Traditional medicine and reproductive health in Africa. Afr J Reprod Health. 2002;6(2):7-12.

9. Araoye OM. Epidemiology of infertility: social problems of the infertile couples. West Afr J Med. 2003;22(2):190-196.

10. Pilcher H. Fertility on a shoestring. Nature. 2006;442(31):975-977.

11. Akinloye O, Akintunde CO, Banjoko SO, Adaramoye AO, Adeleye AO. An assessment of the estrogenic effect of soyprotein on female rabbits. Food Chem. 2002;77:67-69.

12. Akinloye O, Arowojolu AO, Shittu BO, Adejuwon CA. Selenium status of infertile Nigerian males. Biol Trace Elem Res. 2005;104(1):9-18.

13. Akinloye O, Arowojolu AO, Shittu BO, Anetor JI. Cadmium toxicity, a possible cause of male infertility in Nigeria. Reprod Biol. 2006; 6(1):17-26.

14. Aghanwa HS, Dare FO, Ogunniyi SO. Sociodemographic factors in mental disorders associated with infertility in Nigeria. J Psychosom Res. 1999;46(2):117-123.

15. Okonofua F. Female genital mutilation and reproductive health in Africa. Afr J Reprod Health. 2006;10(2):7-12.

16. Nwabuisi C, Onile BA. Male infertility among sexually transmitted diseases clinic attendees in Ilorin, Nigeria. Niger J Med. 2001;10(2): 68-71.

17. Arowojolu AO, Akinloye O, Shittu BO, Adejuwon CA. Correlations between seminal plasma hormones and semen biophysical parameters in infertile males in Ibadan. Trop J Obstet Gynaecol. 2003;20(1):7-11.

18. Arowojolu AO, Akinloye O, Shittu BO, Adejuwon CA. Serum and seminal plasma prolactin level in infertile men. Eur J Obstet Gynecol. 2004;24(3):308-311.

19. Akinloye O, Arowojolu AO, Shittu BO, Abbiyesuku FM, Adejuwon CA. Osotimehin B. Serum and seminal plasma hormonal profiles of infertile Nigerian males. African Journal of Medicine and Medical Sciences. 2006;35(4):468-473. 
20. Akinloye O, Grommoll J, Nieschlag E, Simoni M. Androgen receptor gene $\mathrm{CAG}$ and GGN polymorphisms in infertile Nigerian men. J Endocrinol Invest. 2009;32(10):797-804.

21. Engel W, Adham IM, Nayernia K, Neesen J. Genetic causes of male infertility. Verh Dtsch Ges Pathol. 2004;88:130-135. German.

22. Bledsoe C, Banja F, Hill AG. Reproductive mishaps and Western contraception: an Africa challenge to fertility theory. Population and Developmental Review. 1998;24(1):15-57.

23. Umezulike AC, Efetie ER. The psychological trauma of infertility in Nigeria. Int J Gynaecol Obstet. 2004;84(2):178-180.

24. Murray CJL, Lopez A, editors. The global burden of diseases; 1996. WHO Report. Available from: www.who.int/whr/2002/chapter2/en/ index6.html. Accessed May 14, 2010.

25. Okonofua $F$. The case against new reproductive technologies in developing countries. Br J Obstet Gynaecol. 1996;103(10):957-962.

26. van Balen F, Gerrits T. Quality of infertility care in poor-resource areas and the introduction of new reproductive technologies. Hum Reprod. 2001;16(2):215-219.

27. Okonofua F. New reproductive technologies and infertility treatment in Africa. Afr J Reprod Health. 2003;7(1):7-8.

28. Alubo $\mathrm{O}$. The promise and limits of private medicine: health policy dilemmas in Nigeria. Health Policy Plan. 2001;16(3):313-321.

29. Danis M, Sepinwall A. Regulation of the global marketplace for the sake of health. J Law Med Ethics. 2002;30(4):667-676.

30. WHO. Health and millennium development goals. Geneva: WHO; 2005. Available from: http://books.google.com.qa/books?id=m98ouHZem94 C\&printsec=frontcover $\&$ hl $=$ en $\&$ source $=g b s \_v 2 \_s u m m a r y \_r \& c a d=0 \#$ $\mathrm{v}=$ onepage \&q\&f=false. Accessed May 14, 2010.

31. Gleicher N. Cost-effective infertility care. Hum Reprod Update. 2000; 6(2):190-199

32. Phillips KA, Holtgrave DR. Using cost-effectiveness/cost-benefit analysis to allocate health resources (1997): a level playing field for prevention? Am J Prev Med. 2000;13(1):18-25.

33. Garceau L, Henderson J, Davis LJ, et al. Economic implications of assisted reproductive techniques: a systematic view. Hum Reprod. 2002;17 (12): 3090-3109.

34. Roberts JC. Customizing conception: a survey of preimplantation genetic diagnosis and the resulting social, ethical, and legal dilemmas. Duke Law Technol Rev. 2002:E1.

35. Brauer CA, Rosen AB, Greenberg D, Neumann PJ. Trends in the measurement of health utilities in published cost-utility analyses. Value Health. 2006;9(4):213-218.

36. Bala MV, Zarkin GA, Mauskop F. Conditions for the near equivalence of cost-effectiveness and cost-benefit analysis. Value Health. 2002; 5(4):338-346.

37. Merson MH. The HIV-AIDS pandemic at 25 - the global response. N Engl J Med. 2006;354(23):2414-2417.

38. Kawachi I. QALYs and justice. Health Policy. 1989;13(2):115-120.

39. Sinclair JC. Economic Evaluation of neonatal intensive care: which variables have to be known? Int J Technol Assess Health Care. 1991; 7(Suppl 1):146-150.
40. Karen G, Gavin M. QALY League tables: handle with care. Health Econ. 1992;2:59-64.

41. Donaldson C, Bate A. Resource management. The finite and beyond. Health Serv J. 2000;116(6005):20-21.

42. Johannesson M, O'Connor RM. Cost-utility analysis from a societal perspective. Health Policy. 1997;39(3):241-253.

43. Griebsch I, Coast J, Brown J. Quality-adjusted life years lack quality in pediatric care: a critical review of published cost-utility studies in child health. Pediatrics. 2005;115(5):e601-e614.

44. Al Maiwenn, Feenstra TL, Hout BA. Optimal allocation of resources over health care programmes: dealing with decreasing marginal utility and uncertainty. Health Econ. 2005;14(7):655-667.

45. Doctor JN, Bleichrodt H, Miyamoto J, Temkin NR, Dikmen S. A new and more robust test of QALYs. J Health Econ. 2004;23(2):353-367.

46. Lehmann HP. A new tool for population-based quality-adjusted life years. Med Care. 1998;36(6):775-777.

47. Glannon W, Ross LF. Motivation, risk, and benefit in living organ donation: a reply to Aaron Spital. Camb Q Healthc Ethics. 2005;14(2) 191-194; discussion 195-198.

48. Ashcroft RE. Standing up for the medical rights of asylum seekers J Med Ethics. 2005;31(3):125-126.

49. Ikechebulu JI. Assisted reproduction techniques (ART): the state of art in Nigeria. J Coll Med. 2003;8(1):1-6.

50. Robinson JC. Philosophical origins of the social rate of discount in cost-benefit analysis. Milbank Q. 1990;68(2):245-265.

51. Lawrence E. Poverty and the rate of time preference. J Polit Econ. 1991;99(1):55-77.

52. Tsui BC. A simple method with no additional cost for monitoring ETCO2 using a standard nasal cannulae. Can J Anaesth. 1997;44(7) 787-788.

53. McMillan J. Allocating fertility services by medical need. J Br Fer Soc. 2000;4(1):11-13.

54. Cohen J. Preferences, needs, and QALYs. J Med Ethics. 1996;22(5) 267-272.

55. Sendi P, Gafni A, Birch S. Opportunity costs and uncertainty in the economic evaluation of health care interventions. Health Econ. 2002; $11: 23-31$

56. National Institute of Health and Clinical Excellence (NICE) (2004): fertility: assessment and treatment for people with fertility problems Available from: http://guidance.nice.org.uk/CG11. Accessed May 12, 2010.

57. Schwab ZL, Karungari K. The health consequences of adolescent sexual and fertility behavior in sub-Saharan Africa. Stud Fam Plann. 1998;29(2):210-232.

58. Harsanyi JC. Can the maximin principle serve as a basis for morality? A critique of John Rawls's theory. Am Polit Sci Rev. 1975;69: 594-606.

59. Pearce TO. Women, the state and reproductive health issues in Nigeria. JENdA: a journal of culture and African women studies. 2001:1(1). Available from: http://www.jendajournal.com/vol1.1/pearce.html. Accessed May 13, 2010.
International Journal of Women's Health

\section{Publish your work in this journal}

The International Journal of Women's Health is an international, peerreviewed open-access journal publishing original research, reports, reviews and commentaries on all aspects of women's healthcare including gynecology, obstetrics, and breast cancer. Subject areas include: Chronic conditions (migraine headaches, arthritis, osteoporosis);

\section{Dovepress}

Endocrine and autoimmune syndromes; Sexual and reproductive health; Psychological and psychosocial conditions. The manuscript management system is completely online and includes a very quick and fair peer-review system. Visit http://www.dovepress.com/ testimonials.php to read real quotes from published authors. 